\title{
Birth order as a quantitative expression of date of birth
}

\author{
C-G BERGLIN \\ From Parkgatan 12, S 41138 Gothenburg, Sweden
}

Publications on birth order mostly differ in their findings. In 1874 Galton $^{1}$ stated that firstborn dominated among eminent men. Thirty years later, Pearson ${ }^{2}$ claimed that society was corrupted through the defects of firstborn. Surveys ${ }^{3-9}$ covering hundreds of books and articles give a remarkably inconsistent picture of the influence of sibling position on physical and psychological development. In 1913 Weinberg ${ }^{10}$ showed that methodological slips are an important source of confusing results. One such slip is the idea that the number of older siblings (earlyborn) and the number of younger siblings (lateborn) should balance in the population.

If a total sibship is considered as a unit, beginning at 0 with the oldest sibling and ending at 1 with the youngest one, it is obvious that 0.5 is the exact mean position of its members. The same statement is true for any sample of total sibships but not for a sample consisting of members of different sibships. In fact, Cobb, ${ }^{11}$ as early as 1914 pointed to circumstances that might fundamentally distort birth order balance in the general population, but his warnings were not taken seriously. The consequences have been devastating. Those who have studied the influence of sibling position on disease, character, performance, or fate have mostly used methods based on the Greenwood-Yule model, ${ }^{12}$ with its erroneous assumption of a balanced birth order distribution in the general population. If a researcher found that a group of trait-carriers contained more lateborn than earlyborn, or the reverse, he asked whether the ratio deviated significantly from a $50: 50$ distribution. If so he felt entitled to state that the trait and the skewed distribution ("overrepresentation") had something to do with each other.

\section{Empirical models}

Some investigators have taken the precaution of comparing their propositi with trait-carriers of other types 13 or with "social twins"14 in order to keep as many variables as possible under control. These authors, however, did not look for the reasons why the birth order distribution of their comparison group tended to deviate in a similar manner as that of their propositus group. This remarkable fact cannot be explained by random deviations but indicates regular influences causing a characteristic skewness of birth order distribution in both groups.

\section{Balanced models rejected}

A survey of more than $\mathbf{4 0 0}$ studies ${ }^{15}$ discovered only four authors who have tackled the question why lateborn and earlyborn surge in powerful and seemingly spontaneous waves in cohorts of the general population. Half a century after Cobb, in 1969, Hare and Price ${ }^{16}$ started publishing a series of studies where they presented logical analyses of factors (birth rate, marriage rate, family size) which were expected to influence changes in birth order distribution. Hypotheses concerning the direction of such changes within small and large families, as well as among the unskilled and the more skilled classes, were confirmed by means of a representative sample $(n=10053)$ of the adult population of Great Britain. ${ }^{17}$ In 1971 Birtchnell ${ }^{18}$ explicitly refuted the idea of a 0.5 model. He showed that there were no significant differences between the birth order distribution (corrected for age) of 6000 psychiatric patients and that of 3224 individuals representing the corresponding general population. His findings are the more convincing as he used a non-parametric method for testing significances.

Applying branching process mathematics to the birth order problem, Jagers ${ }^{19}$ concluded, among other things, that total populations contain more lateborn than earlyborn. He remarked that the contribution of statisticians to the unhappy history of birth order studies had not been very glorious.

\section{A quantitative model of skewness}

In 1959, when surveying 607 cases of alcoholism, I found that older alcoholics were mainly older siblings, younger alcoholics chiefly younger siblings. This led to the idea that parents had devoted themselves to bringing forth more earlyborn in the 1890 s, more lateborn in the 1920 s. An analysis of the logical plausibility of the idea made it possible to formulate a numerical model describing not only that the distribution is skewed, but also why, in what 
direction, and to what extent. The model was further tested on a group of doss-house guests. ${ }^{20}$

In 1960, in a survey of 722 cases with various psychiatric diagnoses, Holmgren ${ }^{21}$ performed another cross-validation of the model. His findings confirmed the underlying hypotheses, with one exception: patients aged 17-28 were unexpectedly often $(p=0.07)$ lateborn. Similarly, in a sample I collected in 1973 the numerical predictions agreed closely with the mean positions of 671 patients, except in quite young problem cases who were often $(p=0.24)$ lateborn.

A detailed description of the logical analysis and its numerical form is given in the monograph Regular skewness of birth order distribution. ${ }^{15}$ The results may be summarised as follows. When birth cohort size or family size increase, many earlyborn are produced. A decrease of cohort size or family size entails many lateborn. The model is further dependent on a gross estimation of the average sibling interval that characterises a certain chronological period. These three statistics (number of live births, mean family size, average sibling interval) form the sole basis of the model. The result is an independent estimate of mean sibling position as a measure prediciting the ratio of lateborn in the corresponding cohort of the general population. The higher the value rises, the more lateborn are to be expected in the cohort. A low index value, say 0.46 , indicates a pronounced excess of earlyborn, 0.51 a slight excess of lateborn, and 0.54 a pronounced overweight of lateborn. By using

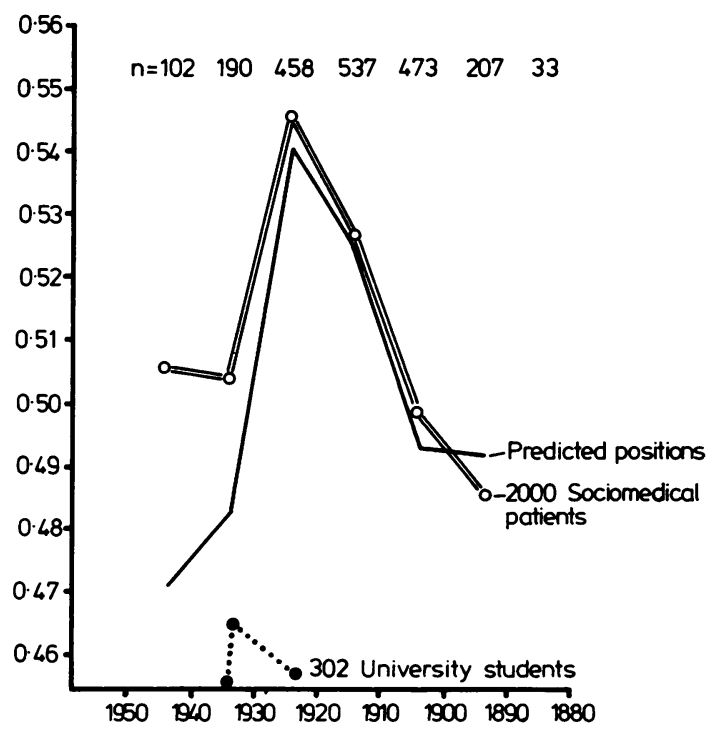

Fig 1 Mean sibling positions 1890-1950. Predicted positions compared with observed positions in 2000 sociomedical patients and in 302 university students. only general demographic sources, the model circumvents the laborious and expensive selection of controls and concentrates on the forces that rule the skewness of sibling distribution. One may then well ask how it can have any validity at all. One answer to the question is the rather close agreement between the predictions of the model and the mean positions observed in a series of subgroups among 2000 problem cases. The observed position of a person with rank $r$ among $s$ children is expressed as $\left(r-\frac{1}{2}\right) / s$. This index ${ }^{20}$ differs somewhat from Slater' $\mathrm{s}^{22}$ index $(r-1) /(s-1)$, according to which the mean position of a sample does not include the position of only children.

The curve of predicted mean sibling positions for each of the decades $1890-1949$, together with the observed mean positions among the problem cases and among 302 university students, was published as fig $7: 9$ in the monograph ${ }^{15}$ and is reproduced here as fig 1 . The model, however, would be still more convincing if it could be shown that its predictions are fulfilled also by values found in cohorts of the general population.

\section{Predictive power of the quantitative model}

I therefore decided to select 600 controls from the general population. They were born at intervals of 18 days during 30 years 1920-49. All controls were resident in Gothenburg, about $50 \%$ of them born in the town, the rest in other parts of Sweden, a few even abroad. The controls were randomly chosen from the official register of the town and approached by telephone, by letter, or by personal visit. More than $90 \%$ answered readily, about $4 \%$ refused, and about as many were not available. In such cases the families of the controls had to be checked in parish registers from their birth until their mothers were 45 years old. It has thus been possible to account for $100 \%$ of the controls. The findings were separately tabulated for women and men over the periods 1920-9, 1930-4, 1935-9, 1940-4, 1945-9. Computations followed the pattern outlined in the monograph in table $5: 3,15$ and the main results appear here in table 1 , where sexes have been pooled. Whereas the 1920-9 findings were registered as a single decade, I decided to divide the next two decades into five-year periods

Table 1 Observed mean sibling position and mean family size in cohorts of the general population

\begin{tabular}{llll}
\hline Cohort & No & Mean pasition & Mean family size \\
\hline $1920-9$ & 200 & $0.5444 \pm 0.0193$ & $2.89 \pm 0.28$ \\
$1930-4$ & 100 & $0.5030 \pm 0.0261$ & $2 \cdot 15 \pm 0.22$ \\
$1935-9$ & 100 & $0.4566 \pm 0.0275$ & $2 \cdot 30 \pm 0.21$ \\
$1940-4$ & 100 & $0.4617 \pm 0.0248$ & $2 \cdot 16 \pm 0.20$ \\
$1945-9$ & 100 & $0.4993 \pm 0.0266$ & $2.45 \pm 0.21$ \\
\hline
\end{tabular}


to study the form of the curve in detail. It soon became obvious that observed mean positions varied sharply even within decades. People sampled from the 1930-4 cohort differed appreciably from those belonging to the 1935-9 cohort with its many earlyborn. Those sampled from the 1940 s showed the reverse pattern in their five-year cohorts.

It now became urgent to check whether the method of prediction had the power to explain also such hitherto unknown phenomena of five-year variation. To this purpose the decades in table $7: 7$ of the monograph ${ }^{15}$ had to be elaborated for five-year periods 1920-50. Sibling intervals $\left(w_{1}\right)$ were interpolated. Official registers supplied the number of live births $\left(N_{1}\right)$ in 1925,1935 , and 1945, as well as the number of live births in each five-year period $\left(\mathrm{N}_{\mathrm{t}}\right)$.

As to mean family size, it presented a certain problem. Initially, the estimated Swedish values used in table $7: 7$ of the monograph were applied. They appear in the first row $\left(\overline{\mathrm{s}}_{1}\right)$ of table 2 , with two exceptions. The mean size of 1935 has been adjusted from $2 \cdot 16$ to 2.23 and that of 1945 from 2.53 to 2.30 . As emphasised in the monograph, mean family size is a complicated concept. How is a family defined, and to which period does it belong? The best estimate would be obtained through direct information about the sibship size of randomly selected birth cohort members, ${ }^{16}$ but a large study is needed. Estimates built on indirect information, as in the present case, are easily biased by sudden fertility changes. It is therefore quite possible that average values such as 2.23 and 2.30 from the basic population in table 1 are more adequate estimates than extreme Swedish national values such as 2.16 and 2.53 . While the observed mean positions in the 1930s dropped from 0.503 to 0.457 (table 1 ), the predicted fall would go from 0.522 to 0.448 with mean size $2 \cdot 16$, but only from 0.517 to 0.453 if mean size 2.23 is accepted. In the 1940 s observed mean position rises from 0.462 to 0.499 . A mean size of 2.53 in 1945 would lead to a predicted rise from 0.421 to 0.514 , but if mean size 2.30 is accepted the rise would be restricted from 0.441 to 0.497 . These differences become impressive when represented graphically.

In table 2 the decade values for $1920,1930,1940$, and 1950 (intervals, cohort size, family size) were transferred directly from table 7:7 of the monograph, ${ }^{15}$ and the five-year values supplied and partly adjusted in the manner just described. The result is a series of predicted mean sibling positions (table 2, last row) compared in fig 2 with the new empirical findings in the general population. (A decade mean is not located exactly halfway between predicted five-year points since it corresponds to five-year means weighted by their $\mathrm{N}_{\mathrm{t}}$-values.)

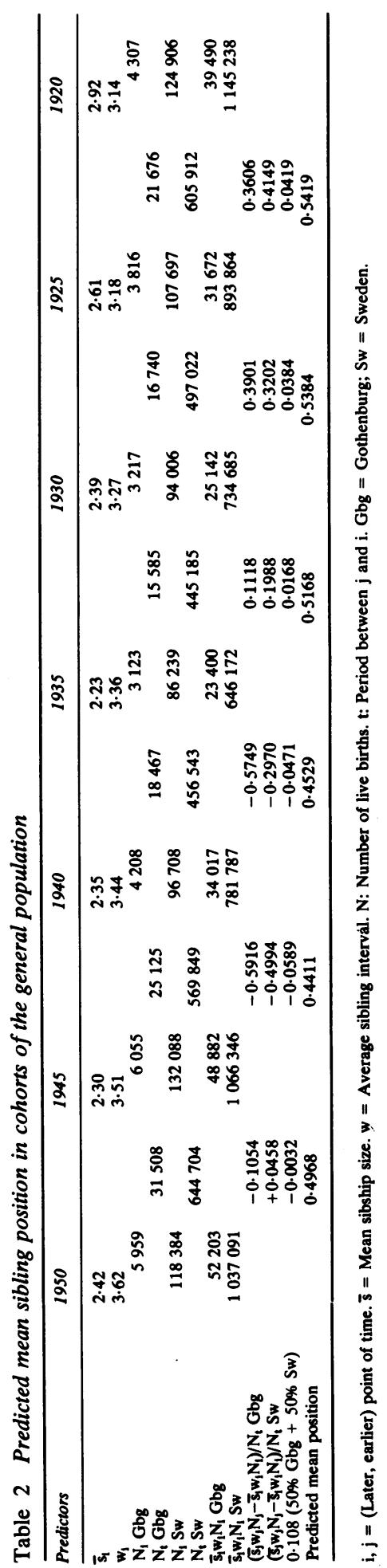




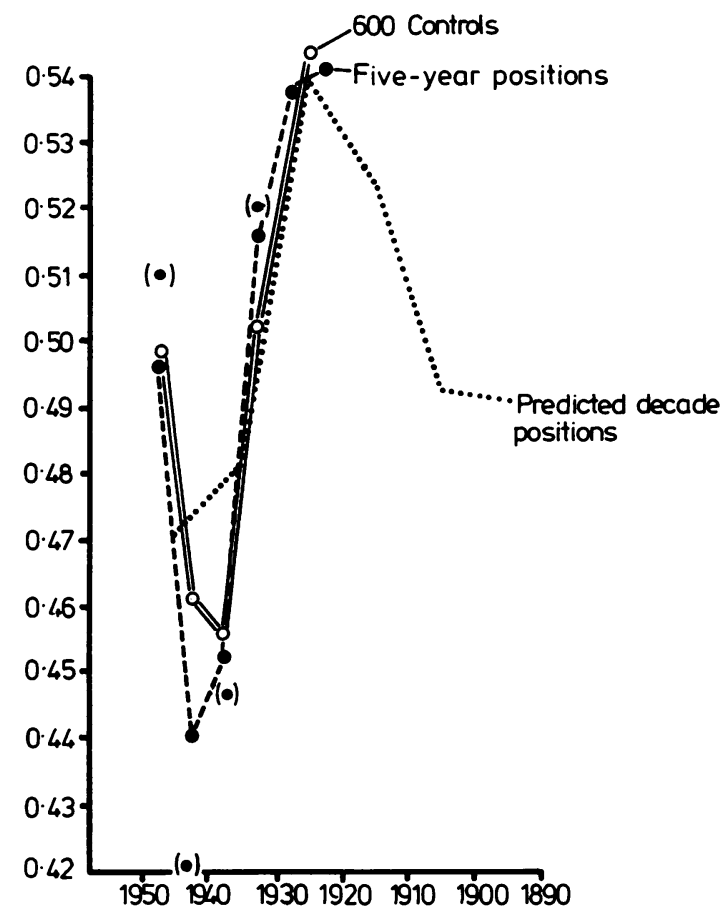

Fig 2 Mean sibling positions 1920-50. Predicted decade positions and five-year positions, compared with observed positions in 600 controls from the general population. Dots in brackets: predicted positions under the assumption of family size $2 \cdot 16$ in 1935 and 2.53 in 1945.

\section{Discussion}

The standard deviation of any sibling position is $\mathbf{0 . 2 8}$ or somewhat less, so that a mean sibling position in 100 siblings has an error of about 0.028 and in 200 siblings an error of about $\mathbf{0 . 0 2 0}$, as in table 1 . A comparison with table 2 shows that the largest difference between observed and predicted decade means occurs in the 1940 s-namely, $0 \cdot 48-0 \cdot 47$, or about five-tenths of the error. During the thrilling months of sampling when new findings slowly accumulated, means changed considerably up to the end. Actually, one single person may move the mean sibling position in 200 persons by one-tenth of the standard error. Hence the vital necessity to ensure complete response.

The present finding of swift and extensive variations of mean sibling position from cohort to cohort makes it necessary to account for birth cohorts in a detailed manner when discussing birth order problems. Differences may rapidly become significant. In our case a difference larger than 0.056 between two decade means $(n=200)$, or larger than
0.068 between a decade mean and a five-year mean ( $n=100$ ), is significant at the $5 \%$ level. The situation occurs when we compare the observed mean of the 1920 s with that of the 1930 s or the 1940 s, as well as with that of the 1935-9 period or the 1940-4 period. If we use the predicted, not the observed, mean of the 1920 s for comparison we attain to the 0.001 level of significance.

Another question seems to be nearing its solution: the finding that problem cases aged 17-28 were remarkably often lateborn. A group of 80 youngsters from the 1930 cohort had a mean position of 0.5351 , thus deviating by $0.0515 \pm 0.0291$ from the predicted mean. The present investigation allows us to state with some confidence that the prediction model really represents general population values. The supposition that lateborn yield more quickly to their problems therefore seems strengthened. One is reminded of Galton's statement in 1874 that firstborn tend to be more enduring and persevering which has found better support than most other alleged birth order differences. Firstborn develop their intelligence somewhat better than others. ${ }^{23}$ University students show a real overrepresentation of firstborn when compared with other members of their birth cohort.

No conclusion in the field of birth order study can be valid without knowledge of the cohort variations of birth order distribution in the corresponding general population. The model discussed here will facilitate this task.

\section{Appendix}

Since the background of table 2 is rather complicated, the following information may be useful.

In the 1925 column, for example, the precise point of time is the first day of $1925(\mathrm{j})$, in the 1930 column, the first day of 1930 (i), $j$ and $i$ defining the period 1925-9 (t).

Mean sibship size at a certain moment $\left(\bar{s}_{1}\right)$ is determined by interpolation from population values of adjacent periods. If values from appropriate general populations are not available, one has to fall back on cohort values of the sample, despite their large errors (cf table 1).

The average sibling interval may be estimated by means of intervals characteristic of sibships of different size. Such intervals tend to remain fairly constant. I have used a list of Swedish intervals, reproduced in table 3 . If a cohort sample contains, say, 34 people from families with four children, the relative number of such families in the sample is $\mathrm{n} / \mathrm{s}=34 / 4$, each family covering $(\mathrm{s}-1)=3$ intervals with the average length $\left(w_{8}\right)$ of $3 \cdot 26$ years. The sum of interval lengths in these sibships of four is 
Table 3 Empiric average sibling intervals in 530 Swedish sibships

\begin{tabular}{|c|c|c|c|c|c|c|c|c|}
\hline \multirow{2}{*}{$\begin{array}{l}\text { Sibship size, } \mathrm{s} \text { siblings } \\
\text { Average sibling interval, } \mathrm{w}_{\mathrm{s}} \text { years }\end{array}$} & 2 & 3 & 4 & 5 & 6 & 7 & $8-10$ & $\geqslant 11$ \\
\hline & $4 \cdot 72$ & $4 \cdot 21$ & $3 \cdot 26$ & $3 \cdot 12$ & 2.95 & $2 \cdot 60$ & $2 \cdot 34$ & $2 \cdot 11$ \\
\hline
\end{tabular}

$\mathrm{w}_{\mathrm{s}}(\mathrm{s}-1) \mathrm{n} / \mathrm{s}=3.26 \times 3 \times 34 / 4=83.13$ years. The sum total for all family sizes, $\Sigma\left[w_{s}(s-1) n / s\right]$, is finally divided by the total number of intervals in the sample, $\Sigma[(s-1) n / s]$, in order to arrive at an estimate of the average interval of the period, $w_{t}$. The average interval at a certain moment, $w_{i}$, is then estimated by interpolation.

$N_{1}$ Gbg is the mean number of live births a year in Gothenburg characterising the moment i. For the first day of 1925 all births occurring in the four years 1923-6 are summed and divided by four and this smoothed mean entered into the table. $\mathrm{N}_{\mathrm{t}} \mathrm{Gbg}$ simply registers the total number of live births in Gothenburg for the corresponding period-for example, 1925-9.

In the expression $\left(\mathrm{S}_{j} \mathrm{w}_{j} \mathrm{~N}_{\mathrm{j}}-\mathrm{S}_{\mathrm{i}} \mathrm{w}_{\mathrm{i}} \mathrm{N}_{\mathrm{i}}\right) / \mathrm{N}_{\mathrm{t}}$ the $\mathrm{j}$-values apply to 1925 , the $\mathrm{i}$-values to 1930 , the $\mathrm{t}$-values to $1925-9$, thus for Gothenburg $(2.61 \times 3.18 \times$ $3816-2.39 \times 3.27 \times 3217) / 16740=0.3901$. The rationale behind the expression, as well as behind the

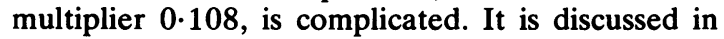
detail in chapter 7 of the monograph. ${ }^{15}$

Since roughly $50 \%$ of the studied population are natives of the town, half the Gothenburg value, $0 \cdot 3901$, and half the general Swedish value, 0.3202 , are ultimately combined and weighted by $0 \cdot 108$, forming the predicted deviation from 0.5000 of the mean sibling position in the 1925-9 cohort.

\section{References}

${ }^{1}$ Galton F. English men of science. London: Macmillan, 1874.

${ }^{2}$ Pearson K. On the handicapping of the first-born. London: Cambridge University Press, 1914.

${ }^{3} \mathrm{Hsiao} \mathrm{H}$. The status of the first-born with special reference to intelligence. Genet Psychol monogr 1931; 9: 3-118.

${ }_{4}^{4}$ Jones HE. Order of birth in relation to the development of the child. In: Murchison C. Handbook of child psychology. Worcester, Mass: Clark University Press, $1931 ; 204-41$
${ }^{5}$ Murphy G, Murphy LB, Newcomb TM. Experimental social psychology, New York: Harper, 1937: 348-67.

${ }^{6} \mathrm{Chen} \mathrm{E}$, Cobb S. Family structure in relation to health and disease. J Chron Dis 1960; 12: 544-67.

${ }^{7}$ Sampson EE. The study of ordinal position: antecedents and outcomes. Progress in experimental personality research. New York: Academic Press, 1965; 2: 175228.

${ }^{8}$ Miley CH. Birth order research 1963-67, bibliography and index. J Individ Psychol 1969; 25: 67-70.

${ }^{9}$ Vockell EL, Felker DW, Miley CH. Birth order literature 1967-71, bibliography and index. J Indiv Psychol 1973; 29: 39-53.

${ }^{10}$ Weinberg W. Die Kinder der Tuberkulösen. Leipzig: Hirzel, 1913.

${ }^{11} \mathrm{Cobb} \mathrm{JA}$. The alleged inferiority of the first-born. Eugenics Review 1914; 5: 357-9.

${ }^{12}$ Greenwood M jr, Yule GU. On the determination of size of family and of the distribution of characters in order of birth from samples taken through members of the sibships. Journal of the Royal Statistical Society 1914; 77: 179-99.

${ }^{13}$ Norton A. Incidence of neurosis related to maternal age and birth order. British Journal of Social Medicine 1952; 6: 253-8.

${ }^{14}$ Inghe G. Fattiga $i$ folkhemmet. Uppsala: Almqvist and Wiksell, 1960.

${ }^{15}$ Berglin C-G. Regular skewness of birth order distribution. Scand J Soc Med 1981; suppl 23. (Contains a bibliography of 434 works.)

${ }^{16}$ Hare EH, Price JS. Birth order and family size: bias caused by changes in birth rate. Br J Psychiatry 1969; 115: 647-57.

${ }^{17}$ Hare EH, Price JS. Birth order and birth rate: findings in a representative sample of the adult population of Great Britain. J Biosoc Sci 1974, 6: 139-50.

${ }^{18}$ Birtchnell J. Birth rank and mental illness. Nature 1971; 234: 485-7.

${ }^{19}$ Jagers P. How probable is it to be firstborn? And other branching process applications to kinship problems. Mathematical Biosciences 1982; 59: 1-15.

${ }^{20}$ Berglin C-G. Femtio härbärgesklienter med socialhjälp. Socialmedicinsk tidskrift 1960, 37: 295-9.

${ }^{21}$ Holmgren L. Om syskonplacering, syskonantal och social missanpassning. Gothenburg: Graduate School for Social Work and Public Administration, 1960.

${ }^{22}$ Slater E. Birth order and maternal age of homosexuals. Lancet 1962; i: 69-71.

${ }^{23}$ Zajonc RB, Markus GB. Birth order and intellectual development. Psychol Rev 1975; 82: 74-88. 